\title{
Cultural Marker Identification for Web Application Design Targeted for Malaysian Multicultural Users
}

\author{
Norliza Saidin $^{\# 1}$, Dalbir Singh ${ }^{\# 2}$, Zainul Akramin Mohd Drus ${ }^{\# 3,}$ Rahmat Hidayat ${ }^{*}$ \\ ${ }^{\#}$ Research Center for Software Technology and Management (SOFTAM), Faculty of Information Science and Technology, University \\ Kebangsaan Malaysia, UKM, Bangi Selangor, 43600, Malaysia \\ E-mail: ${ }^{1}$ nollyza@yahoo.com; ${ }^{2}$ dalbir@ukm.edu.my; ${ }^{3}$ lilmukramin@siswa.ukm.edu.my \\ * Department of Information Technology, Politeknik Negeri Padang, Padang, Sumatra Barat, Indonesia \\ E-mail: rahmat@polinpdg.ac.id
}

\begin{abstract}
The rapid growth of technology result in two contradictory phenomena, the global world becomes smaller while the internet users increase drastically. This diversity of users becomes the main attention toward the study of human-computer interaction due to the influential of users' background toward the usability of web application whereby the combination of color strongly determines user's preference and engagement level. Hence, determination of color based cultural marker is crucial to the interface design process in order to fulfill the need of diverse users. Most of the empirical study so far has been carried in western contextual. As a result, suggested marker are not applicable in eastern perspective, particularly Malaysia which consist of multicultural societies. This article provides a content analysis of the website application targeted to multicultural audience to determine the prominent color based cultural markers. More importantly, identifications of the markers could assist the interface designers towards creating web-based application that reflected the multicultural audience preferences.
\end{abstract}

Keywords - cultural marker; multicultural; user preferences; user interface; cultural factors; cultural element

\section{INTRODUCTION}

The relationship of culture and human plays an important role in the interface design process. Plethora of studies has shown the synchronization between these factors provides positive spillover toward acceptance and usability of webbased applications. There have been agreements among scholars since several decades ago on how culture could influence user's behavior toward technology [1], [2]. For instance, how they interpreted, reacted and felt toward the application were associated with their cultural background. Empirical studies so far confirmed that culture as a precursor to human characteristic; better understanding of the users' cultural background was one key premise to provide successful interaction [3].

Among the issues highlighted, cultural-based user interface dominated the study [4]. It has been noted among prominent scholar, lack understanding of users' cultural backgrounds could undermine the usability of application [5], [6]. The term culturability initiated by Barber and Badre [7] since several decades ago proves how culture and usability could not be separated while designing the web-based application. The concepts of understanding certain applications are varying among users that strongly related to their cultural background, in particular, embedded in their personality.

There are several terminologies used to describe the interface design elements that are common among particular groups: for instance, cultural marker [7], [8] and cultural attractor [9]. However, various researchers utilized cultural marker since several decades ago to imply that various cultural backgrounds could lead to the discovery of different marker. Comprehensive studies so far confirmed that cultural marker was influenced by the local culture [8], [10]. Determination of cultural marker was essential for interface designers in order to provide successful interaction. The markers should be manipulated to suit the user's cultural needs that speed up the understanding process. Color is one of the dominant culture markers that influence user's preference and engagement toward certain interface design.

Thus, the existence of Culture Centered Design (CCD) is an approach that focuses on users' cultural background while designing the interface. Most of the research regarding CCD have been conducted in the west with a few studies focusing on eastern perspective. Moreover, most of the studies focused on finding the differences at a cross-cultural level involving comparison study between two or more countries. Such a study cannot be applied in other countries because 
the studies of culture are related with the context because it opens to ecological fallacy [11]. Even though some studies in Asian countries are available, mostly focusing on China, Taiwan, Korea, and India. People from those countries practice different cultural traits that differ from subcultures in Malaysia. Therefore, the overarching purpose of this paper is to discover color based cultural markers in interface design for a multicultural society in Malaysian perspective.

This article is encompassing of four sections. Section I briefly overviews the importance of cultural marker identification in interface design. Section III reviews previous literature that focused on prominent cultural models and evolution of CCD. Section III also proposes the methodology to discover the color based cultural markers. Result and discussion on the discovery of color based cultural marker are reported in Section III. Finally, section IV presents the conclusion and highlights the future work.

\section{MATERIAL AND METHOD}

\section{A. Cultural Model and Culture Centered Design}

This section reviews the related literature on two main themes regarding the study of culture for interface design; Cultural Model and Culture-Centered Design. The discussions are focused on a critical review of prominent cultural models and the evolutions of CCD research.

1) Cultural Model: Considerable amount of literature has depicted that cultural model used to describe differences among a group of people from geographical segregation which influence their conceptualization to certain stimuli [12], [13]. Nonetheless, by intent or default, all attempt of cultural research will end up with cultural dimension through empirical study. The key underpinning in every research relied on the definition of the cultural model through the measurement of cultural variables which vary among scholars. Among the models, three cultural models were discussed rigorously in literature are from Hofstede [14], Trompenaars \& Hampden-Turner [15] and Hall [16]. The above models were developed in the 1990s provided many facets of culture based research [17].

According to [18], communication is a mechanism to discover the diversity of people. The ways people receive, process and transmit the information varies among different groups of people. Hall belief that most of the interaction processes are using nonverbal communication, either through the way people behave or use certain material. Most cited dimension in his cultural model is High Context and Low Context Culture.

In contrast, [14], as one of the pioneers in cultural research, distinguish the culture by using quantitative study among international workers using cultural dimension. The respective countries were given the score index for every dimension based on the nationality of the workers. Initially, only four dimensions were built; Power Distance, Uncertainty Avoidance, Gender Role Identity and Collectivism Individualism.

Meanwhile, Trompenaars \& Hampden-Turner [15] focuses on finding the differences through observation on how people solve the problem in three different key area; time, environment and relationship. The main purpose of his study is to assist the manager in communication and collaboration. Based on the problem, he discovered the measurement by using seven dimensions.

Apparently, it appears from the aforementioned model that culture was always regarded as major factor contributes to the existence of diversity among people which ranging from their subjective feeling to their behavior. On one hand, different numbers of dimension were developed by the researcher as a measurement of diversity among human. On the other hand, several dimension share similarities across discipline disregard the domain of the study. For instance, Power Distance and Collectivism Individualism [14] have similarities with High Context/ Low Context Cultures [16]. Polychromatic, Time Orientation, and Sequential Synchronic show dimension relating to the passage of time.

2) Evolution of Culture Centered Design (CCD): More than 20 years pass by since Hofstede [14] discovered cultural dimension as a variable to measure the psychological differences among human being. He argues that the differences occurred when a group of people living in different context resulting their contrasting cultural trait. Since then a plethora of studies has been conducted to identify the differences and similarities involving several levels [3], [19]. Cross cultural study involved finding differences between two or more different countries or region [20], [21], meanwhile intercultural level involved finding differences within a single country [22], [23]. Since then ample of study regarding culture in interface design has been extensively explored. [9] develop cultural attractor to find the similarities between western and eastern culture. Jagne \& Smith-Atakan [24] discovered prominent interface between four regions, Chiu et al. [23] found differences in the trading websites in China.

Deliberate study of culture is important due to the nature of people reaction to certain stimuli that impress their attention. Most of the scholar agrees that culture plays a significant role in promoting positive stimuli toward human brain [25]. As a result, self-actualization which is the highest peak of Maslow hierarchy of human need will be achieved when correct stimuli trigger spontaneous thinking [26]. More importantly, cultural based user interface design will speed up the human thinking process and reflected through their behavior.

CCD refers to the comprehensive study of users' cultural background to ensure usability of web based application. During the investigation of users background, culture and context are bound together due to the characteristics of culture are not applicable to other settings [4]. With this reason, the study of CCD is increasing. Several terminologies were used by researcher throughout the year to describe the differences, however recently the term culture centered design (CCD) was introduced by [22] when studying the choices of metaphors in Taiwan. Since then the term has been utilized rigorously in the literature [26], [27]. For example [19] trying to find the differences in four western countries. Although various research captured the concept of culture, however, mechanisms on finding the differences remain questionable to the researcher in different context. 


\section{B. Multicultural Society in Malaysia}

The diversity in Malaysia population was noticeable since the early century of Malacca Sultanate period [28]. Indeed, Tanah Melayu was situated in a strategic geographical position along the trade routes of the South East and the Far East became attractive to the travelers. Furthermore, rich resources of Tanah Melayu lures entrepreneurs exchanging their good [29]. However, during this time the migration did not change the cultural structure [30].

In fact, the existence of multicultural society in Malaysia was started during British colonial policy period of divide and rule [28]. The vast changes in Malaysia history happen during this period where large scales of workers were brought in from India and China. Chinese immigrant became laborers in tin mines while Indian became laborers in rubber plantation [31]. As a consequence, the influx of workers shifts the original Malay population to the multinational and multicultural society, primarily consist of three main ethnic groups which are Malays, Chinese and Indians as shown in Fig. 1 [32].

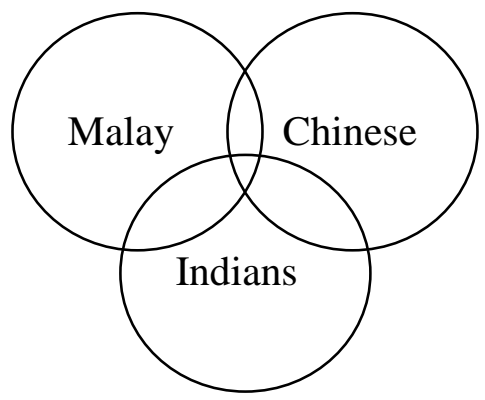

Fig. 1 Multicultural society in Malaysia

Plural society or multicultural society is firstly introduced by J.S. Furnivall commonly used to describe a society that were separated by race, institutional and cultural patterns [33], [34]. The migration of workers bring along their heritage, belief, ritual and religious. They start their family and generate the heterogeneous to the culture of Malaysia when every group tends to socialize in their own society and freely practice their own culture. Although the society change into unique varieties but they are free to involve in their own social activities and practice their own tradition, language, customs, and life style [35], [36]. Hence, this makes Malaysia, an emerging country with a diverse sociocultural background. The plural society which initially started as a worker shifts toward resident eventually builds the Malaysian multicultural society [37]. To live in the peaceful country, mutual respect exists among people of different culture and religion [38].

Research by a well-known scholar conducted a comprehensive study on how values in the workplace are influenced by culture [39]. He explores the Malaysian culture through the view of the 6-D Model. The six dimensions are shown in Fig. 2, which are power distance, individualism, masculinity, uncertainty avoidance, long term orientation and indulgence. These dimensions are discussed below.

1). Power Distance: In the first dimension, Malaysia scored extremely high. This indicates that people in this country accept a hierarchical order which everyone has a place and no further justification needed. The findings show that hierarchy in an organisation causes the existence of inequalities, centralization, subordinates following orders and autocratic leadership.

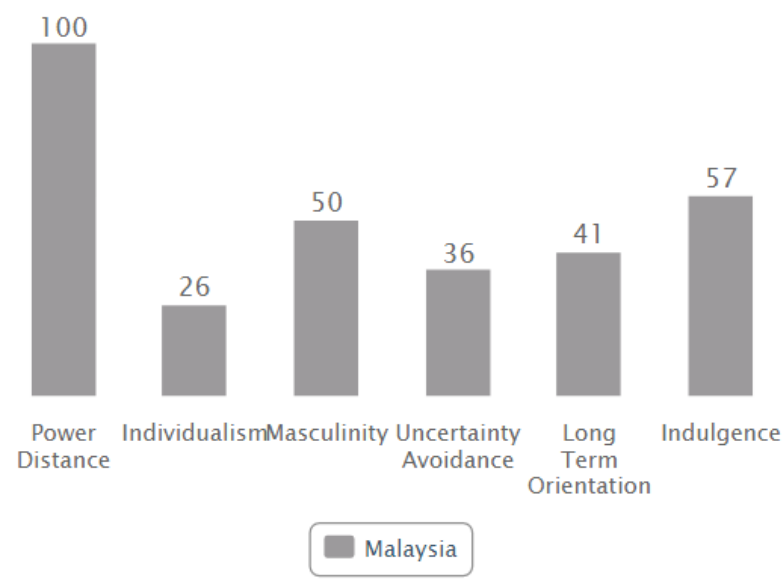

Fig. 2 Malaysian culture through the lens of the 6-D model@

2). Individualism: Low score shows that Malaysia is a collectivistic society. Obviously, Malaysian prefer close long-term commitment towards an organisation. Devotion in collectivistic culture is dominant and overcomes most other societal rules and regulations. Such a society nurtures strong relationships, where everyone is responsible for their fellow group members.

3). Masculinity: This dimension is unable to be determined due to an intermediate score of 50 .

4). Uncertainty Avoidance: In this dimension, Malaysia scored 36 and hence has a low preference for avoiding uncertainty. This shows that Malaysian societies preserve calm attitude, whereby, practice counts more than principles and deviance from the norm tolerated more easily.

5). Long Term Orientation: Malaysia scores 41 in this dimension, which shows that Malaysian practice normative culture. Malaysian have a firm concern with establishing the absolute Truth and their thoughts are normative. They are respectful of traditions, small tendency to save for the future, and emphasise on accomplishing instant results.

6). Indulgence: This dimension scored 57 shows that indulgence plays a vital role. Malaysians are classified as an optimistic society that enjoys and cherishes life. They have a tendency toward finer things and emphasize on leisure in their life.

\section{Methodology}

The applied methodology aims at finding the prominent color based cultural element for the specific cultural group. The element will become a color based cultural marker for the targeted audience and will be used further in the next stage of the study. The significant findings of website analysis are to highlight the relevant color based cultural marker in the existing website by using content analysis 
methodology. Fig. 3 shows the steps that lead to the identification of these color based cultural markers on website application. The selection of the applied methodology in each phase is justified in the following subsection.

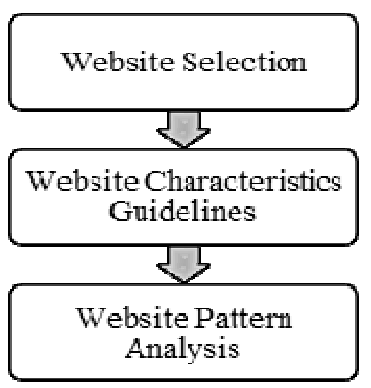

Fig. 3 Website analysis procedure

1) Website Selection: To analyze the culture differences among the subculture in Malaysia, 90 websites were chosen according to their related audience. 30 websites from each audience (Malay, Chinese and Indian) are listed based on three genres (News and Media, Political and Association, Business). Research by several scholars has divided the genre based on the similarities of that particular genre whereby the genre co-exists in the other culture. In a similar study, Fraternali and Tisi [40] focused on an e-commerce website to find the differences between eastern and western culture. Meanwhile, Gould, Zalcaria and Yusof [41] use transportation, education and business for comparison study between Malaysia and United Kingdom. Juric, Kim, and Kuljis [8] however used four genres (e-government, news, and media, business and education) to represent the differences between South Korea and the United Kingdom.

Selections of the genres are based on intercultural perspective rather than cross cultural context. Furthermore, the selections of the genres are also based on a certain distinct characteristic of cross cultural context in Malaysia. It is also justified by Asma [42] that claimed the differences among subcultures in Malaysia can be seen through language, dressing, food, religion, beliefs, aspirations and challenges. Table 1 shows the genre and the number of website for subcultures in this study.

TABLE I

WEBsite GENRE AMONG AUdIENCE

\begin{tabular}{|l|c|c|c|c|}
\hline & Malay & Chinese & Indian & Total \\
\hline $\begin{array}{l}\text { News and } \\
\text { Media }\end{array}$ & 10 & 10 & 10 & 30 \\
\hline $\begin{array}{l}\text { Political and } \\
\text { Association }\end{array}$ & 10 & 10 & 10 & 30 \\
\hline Business & 10 & 10 & 10 & 30 \\
\hline Total & 30 & 30 & 30 & 90 \\
\hline
\end{tabular}

The selections of the website are based on website ranking using www.alexa.com and www.ranking.com. However, due to some limitation, a keyword search was used as an alternative to finding the website. The ranking utilized in this study based on two reasons. First, ranking indicate the popularity, shows that the chosen websites are frequently used by users [43]. Secondly by using ranking and keyword search in selecting the appropriate website also guards against common method variance [44] by trying to avoid randomly choosing the web application. Furthermore, to control the number of websites, this study uses only .my website domain. Fig. 4 shows the flow chart of the website selection methodology.

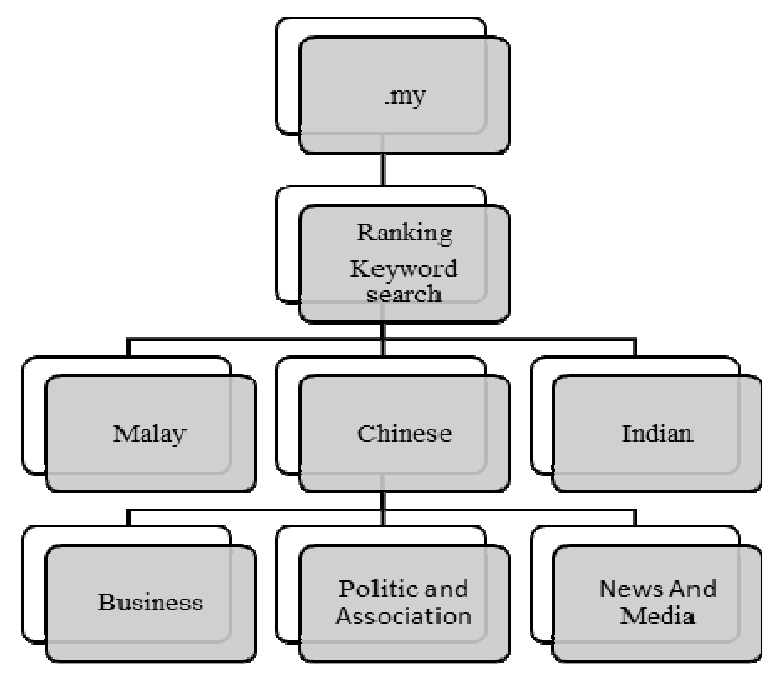

Fig. 4 Website selection methodology

2) Website Characteristic: The selected website was assessed using website characteristic guidelines. Website characteristics focus on elements of user interface design centered on the color based cultural marker as proposed by Barber and Badre [7] and several other researchers [10], [45]. These elements were selected based on the highest frequency of occurrence in cultural based research in the past 10 years. The characteristic of every element is derived from Research Based Web Design and Usability Guidelines [46] and Aaron Marcus \& Gould Interface Guidelines [47]. Based on these guidelines, characteristic of every element are further investigated to determine the characteristic that influences the users with various cultural backgrounds. Hence, characteristic of every element is listed in Table 2.

TABLE II

SUMMARY OF COLOR BASED CHARACTERISTICS IN INTERFACE ELEMENT IN WEBSITE CHARACTERISTICS GUIDELINES BASED ON [48][6]

\begin{tabular}{|l|}
\hline \multicolumn{1}{|c|}{ Color } \\
\hline Page Background \\
Header background \\
Title Text \\
Body Text \\
Link \\
Menu color \\
Banner \\
Dominant Color \\
\hline
\end{tabular}


Using the interface features, color based website characteristic guideline was developed in detail. This guideline will be used to analyze interface pattern in selected website. Characteristic of every element was validated by three experts (interface design expert, ethnicity expert and statistical expert) to ensure the guidelines are applicable interm of finding the interface pattern.

3) Website Pattern Analysis: Based on the guideline above, colour based interface design elements and preferences were observed through a pattern of occurrence for every characteristic in the selected web application. Comparative analysis was conducted between web application which targeted to three main audiences (Malay, Chinese and Indian) based on the number of frequency obtained. During the analysis, only main page of the websites is analysed. Kruskal-Wallis test was administered in order to identify the significant differences between subcultures [49]. This test is nonparametric equivalent to one-way analysis of variance
(ANOVA) which used to test two or more groups was utilized based on following justification:

- Measurement of data is not normally distributed (mean and standard deviation cannot be used to describe parameters)

- Data obtain are a categorical variable which is either dichotomy or ordinal variable which indicate the use of non-parametric test.

\section{RESULT AND DISCUSSION}

A. Color

Kruskal Wallis test on Color preferences among multicultural audience revealed a significant effect for 6 characteristics from 8 characteristics with value range $(\chi 2$ (2) $=7.7$ to $14.4, \mathrm{p}<0.001$ to 0.02 ). The summaries of the result are in Table 3.

TABLE III

WEBsite GENRE AMONG AUDIENCE

\begin{tabular}{|l|c|c|c|c|c|c|}
\hline & $\begin{array}{c}\text { Page } \\
\text { Background }\end{array}$ & Title Text & Roll Over & Unvisited & Menu Color & Banner \\
\hline Chi-Square & 9.901 & 7.705 & 8.378 & 9.048 & 14.400 & 10.904 \\
\hline Df & 2 & 2 & 2 & 2 & 2 & 2 \\
\hline Asymp. Sig. & .007 & .021 & .015 & .011 & .001 & .004 \\
\hline
\end{tabular}

Follow-up tests were conducted using Mann-Whitney [50] with Bonferroni [51] correction to evaluate pairwise comparison among the three groups. The results of this test shows color preferences among Malay and Chinese was significant for 6 characteristics, contrastingly only 3 characteristics were significant between Malay and Indian, likewise, Chinese and Indian only significant in two characteristics as shown Tables 4, 5 and 6.

TABLE IV

Website GENRE AMONG AUdiEnCE

\begin{tabular}{|l|c|c|c|}
\hline & Page Background & Unvisited Link & Menu Colour \\
\hline Mann-Whitney U & 296.500 & 303.500 & 241.500 \\
\hline Wilcoxon W & 761.500 & 768.500 & 706.500 \\
\hline Z & -2.366 & -2.199 & -3.137 \\
\hline Asymp. Sig. (2-tailed) & .018 & .028 & .002 \\
\hline
\end{tabular}

TABLE V

COLOR DifFERENCES BETWEEN MALAY AND CHINESE

\begin{tabular}{|l|r|r|r|r|r|r|}
\hline & Page Background & Title Text & \multicolumn{1}{c|}{ Roll Over } & \multicolumn{1}{c|}{ Unvisited } & \multicolumn{1}{c|}{ Menu color } & Banner \\
\hline Mann-Whitney U & 259.500 & 277.500 & 263.500 & 262.500 & 224.500 & 244.000 \\
\hline Wilcoxon W & 724.500 & 742.500 & 728.500 & 727.500 & 689.500 & 709.000 \\
\hline Z & -2.938 & -2.606 & -2.807 & -2.814 & -3.401 & -3.128 \\
\hline Asymp. Sig. (2-tailed) & .003 & .009 & .005 & .005 & .001 & .002 \\
\hline
\end{tabular}


TABLE VI

COLOR DIFFERENCES BETWEEN INDIAN AND CHINESE

\begin{tabular}{|l|r|r|}
\hline & \multicolumn{1}{|c|}{ Title Text } & \multicolumn{1}{c|}{ Banner } \\
\hline Mann-Whitney U & 335.000 & 305.500 \\
\hline Wilcoxon W & 800.000 & 770.500 \\
\hline Z & -1.756 & -2.202 \\
\hline Asymp. Sig. (2-tailed) & .079 & .028 \\
\hline
\end{tabular}

From the above result from 8 characteristics of colour, only 6 characteristics were significant (Page Background, Title Text, Body Text, Link, Menu colour, Banner colour) and become a cultural marker in this study. Indirectly, these are the prominent colour based cultural makers. Thus, dominant color and header background are not considered significant colour based cultural markers. This finding revealed that there are differences in the preferences of colour features among three subcultures in Malaysia as shown in Table 7.

TABLE VII

SUMMARY OF PROMINENT COLOUR BASED CULTURE MARKERS

\begin{tabular}{|l|}
\hline \multicolumn{1}{|c|}{ Color } \\
\hline Page Background \\
Title Text \\
Body Text \\
Link \\
Menu color \\
Banner \\
\hline
\end{tabular}

\section{IV.CONCLUSION}

The primary objective of this article was to identify web application preferences, especially color based cultural markers among subcultures in Malaysia. This study used content analysis of web application by using website interface guideline. Based on the guideline, differences among the three cultural groups were explored. The result obtains from this comparative study brought many interesting findings. Color based cultural marker exerts its effect on various cultural backgrounds, particularly through interface design preferences. We sought evidence by using Kruskal-Wallis test and further employed Mann Whitney to find the pairwise comparison. Indeed, consistent with the cultural model, subcultures bring diversity toward interface preferences. Importantly we have also uncovered a process to determine color based cultural marker in a multicultural country, particularly Malaysia.

For future works, it is that recommended to investigate other interface elements for website design aimed at multicultural society, especially Malaysia. The findings of these interface elements for website design would improve user acceptance level and further improve continuous engagement. Furthermore, website designers would utilize prominent cultural markers based on interface elements to develop a suitable website design that is intended for a specific group of users that shares common cultural characteristics. Table 8 exhibits other cultural markers for language, page layout, navigation and images besides color that is worthy of further exploration.

TABLE VIII

SUMMARY OF PROMINENT MARKERS FOR FURTHER EXPLORATION

\begin{tabular}{|c|c|c|c|}
\hline Language & $\begin{array}{l}\text { Page } \\
\text { Layout }\end{array}$ & Navigation & Images \\
\hline $\begin{array}{l}\text { Language } \\
\text { use } \\
\text { How many } \\
\text { languages } \\
\text { The } \\
\text { dominant } \\
\text { language } \\
\text { Translation } \\
\text { available } \\
\text { Headlines } \\
\text { Point form } \\
\text { Paragraph } \\
\text { Live Chats } \\
\text { Official } \\
\text { Slogan } \\
\text { Orientation } \\
\text { of Text } \\
\text { Speech } \\
\text { Topics }\end{array}$ & $\begin{array}{l}\text { Banner } \\
\text { Menu } \\
\text { Logo } \\
\text { Title } \\
\text { Search } \\
\text { Menus Type } \\
\text { Menus } \\
\text { Position } \\
\text { Use of } \\
\text { Frames } \\
\text { Static } \\
\text { Banner } \\
\text { Arrangement } \\
\text { Page } \\
\text { Orientation } \\
\text { Page Length } \\
\text { Total } \\
\text { amount of } \\
\text { item in home } \\
\text { page } \\
\text { Display } \\
\text { Density }\end{array}$ & $\begin{array}{l}\text { Navigation } \\
\text { tool } \\
\text { Menu } \\
\text { Link Type } \\
\text { Link Open } \\
\text { Link Clues } \\
\text { Link option } \\
\text { Link choice } \\
\text { access } \\
\text { authentication } \\
\text { Return home } \\
\text { button } \\
\text { Keyword } \\
\text { Search } \\
\text { Scroll Bar }\end{array}$ & $\begin{array}{l}\text { People } \\
\text { Building } \\
\text { Images } \\
\text { Description } \\
\text { Types of } \\
\text { Images } \\
\text { Organization } \\
\text { Stamp } \\
\text { Ratio of } \\
\text { Image } \\
\text { people to } \\
\text { building }\end{array}$ \\
\hline
\end{tabular}

\section{ACKNOWLEDGMENT}

The researcher would like to express appreciation to Malaysian Ministry of Education for their research funding. Research grant: Exploratory Research Grant Scheme (ERGS): ERGS/1/2012/TK06/UKM/02/3.

\section{REFERENCES}

[1] D. E. Leidner, "A Review of Culture in Information Systems Research: Toward a Theory of Information Technology Culture Conflict," MIS Q., vol. 30, no. 2, pp. 357-399, 2006.

[2] M. O. Robert, C. Melissa, Y. . C. Patrick, M. Ann, and P. Mitzi, Montoya-Weiss Mark, "From the User Interface to the Consumer Interface: Results From a Global Experiment," Int. J. Hum. Comput. Stud., vol. 53, no. 4, pp. 611-628, 2000.

[3] J. Noiwan and A. F. Norcio, "Cultural Differences on Attention and Perceived Usability: Investigating Color Combinations of Animated Graphics," Int. J. Hum. Comput. Stud., vol. 64, no. 2, pp. 103-122, 2006.

[4] I. Lee, J. Kim, B. Choi, and S.-J. Hong, "Measurement Development for Cultural Characteristics of Mobile Internet Users at the Individual Level," Comput. Human Behav., vol. 26, no. 6, pp. 1355-1368, 2010.

[5] A. O. Daniel, A. Oludele, R. Baguma, and T. Van Der Weide, "Cultural Issues and Their Relevance in Designing Usable Websites,' Int. J. Innov. Technol. Creat. Eng., no. February, pp. 20-29, 2011.

[6] A. Marcus, "Cross-Cultural User-Experience Design," in SIGGRAPH Asia 2011 Courses, ACM, Hong Kong, China, 2011, pp. 1-201.

[7] W. Barber and A. Badre, "Culturability: The Merging of Culture and Usability," in Proceedings of the 4th Conference on Human Factors and the Web, 1998, pp. 1-14. 
[8] R. Juric, I. Kim, and J. Kuljis, "Cross cultural Web design: An Experiences of Developing UK and Korean Cultural Markers," Proc. Int. Conf. Inf. Technol. Interfaces, ITI, pp. 309-313, 2003.

[9] A. Smith, L. Dunckley, T. French, S. Minocha, and Y. Chang, "A Process Model for Developing Usable Cross-Cultural Websites," Interact. Comput., vol. 24, no. 4, pp. 174-187, 2004.

[10] E. Callahan, "Cultural Similarities and Differences in the Design of University Web sites," J. Comput. Commun., vol. 11, no. 1, pp. 239$273,2005$.

[11] J. Georgas and J. W. Berry, "An Ecocultural Taxonomy for CrossCultural Psychology," Cross-Cultural Res., vol. 29, no. 2, pp. 121$157,1995$.

[12] T. Clemmensen and T. Plocher, "The cultural usability (CULTUSAB) project: Studies of cultural models in psychological usability evaluation methods," in Usability and Internationalization, Pt 1 , Proceedings, 2007, vol. 4559, pp. 274-280.

[13] K. Nasir, N. H. Mohd Ariffin, and F. Muslihah Shuib, "User interface design using cognitive approach: A case study of Malaysian government web portal," in 2010 International Conference on User Science and Engineering (i-USEr), 2010, pp. 174-178.

[14] G. Hofstede, Cultures and Organizations: Software of the Mind. McGraw-Hill, New York, 1997.

[15] F. Trompenaars and C. Hampden-Turner, Riding the Waves of Culture: Understanding Diversity in Global Business. Nueva York: Mc Graw Hill, 1998.

[16] E. T. Hall, "The Hidden Dimension," in Doubleday \& Co, Garden City: Doubleday \& Co, 1966.

[17] P. A. Young, "The Culture Based Model: Constructing a Model of Culture," Educ. Technol. Soc., vol. 11, no. 2, pp. 107-118, 2008.

[18] E. T. Hall and M. R. Hall, Understanding Cultural Differences. Nicholas Brealey International, 1990.

[19] I. Burgmann, P. J. Kitchen, and R. Williams, "Does culture matter on the web?," Mark. Intell. Plan., vol. 24, no. 1, pp. 62-76, 2006.

[20] J. M. Alostath, M. K. Metle, L. Al Ali, and L. R. A. Abdullah, "Cross-Use Pattern Language: Cross-Cultural User Interface Development Tool," Procedia Comput. Sci., vol. 3, pp. 1541-1550, 2011.

[21] C. Olaverri-Monreal and K. J. Bengler, "Impact of Cultural Diversity on The Menu Structure Design of Driver Information Systems: A Cross-Cultural Study," IEEE Intell. Veh. Symp. Proc., no. Iv, pp. 107-112, 2011.

[22] S. T. Shen, M. Woolley, and S. Prior, "Towards Culture-Centred Design," Interact. Comput., vol. 18, no. 4, pp. 820-852, 2006.

[23] W. Chiu, L.-S. Chu, P. Lin, H.-R. Chi, and H.-N. Chiu, "Comparing Cultural Differences in Trading Website Management Between Mainland China and Taiwan," in 2012 9th International Conference on Service Systems and Service Management (ICSSSM 2012), 2012, pp. $2-5$.

[24] J. Jagne and A. S. G. Smith-Atakan, "Cross-Cultural Interface Design Strategy," Univers. Access Inf. Soc., vol. 5, no. 3, pp. 299-305, 2006.

[25] G. Ford and P. Kotzé, "Designing Usable Interfaces with Cultural Dimensions," Human-Computer Interact. - INTERACT 2005, vol. 3585, no. September 2005, pp. 350-363, 2005.

[26] D. Yiwen and M. Guobing, "Culture-Centered Design: Cultural Factors in Interface Usability and Usability Tests," in Proceedings SNPD 2007: Eighth ACIS International Conference on Software Engineering, Artificial Intelligence, Networking, and Parallel/Distributed Computing, 2007, vol. 1, pp. 843-847.

[27] G. van der Veer, "Culture Centered Design," in Proceedings of the 9th ACM SIGCHI Italian Chapter International Conference on Computer-Human Interaction: Facing Complexity (CHItaly), 2011, pp. 7-8.

[28] K. K. Kim, "The Emergence of Plural Communities in the Malay Peninsula before 1874.” Multiethnic Malaysia: Past, Present, and Future. MIDAS, 2009.
[29] Z. Ahmad and N. Ahmad, "Urbanism , Space and Human Psychology: Value Change and Urbanization in Malaysia," Eur. J. Soc. Sci., vol. 11, no. 3, pp. 464-470, 2009.

[30] J. P. Ongkili, Nation-building in Malaysia, 1946-1974. Singapore: Oxford University Press, 1985.

[31] A. R. Embong, Rethinking Ethnicity and Nation-Building: Malaysia, Sri Lanka \& Fiji in comparative perspective. Persatuan Sains Sosial Malaysia, 2007.

[32] A. H. Roslan, "Income inequality, poverty and development policy in Malaysia," Conf. Poverty Sustain. Dev., no. November, p. Vol. 4, 2001.

[33] M. Dhaouadi and C. E. Abraham., "Divide and Rule: The Roots of Race Relations in Malaysia," Asian J. Soc. Sci., vol. 29, no. 1, pp. 177-179, 1997.

[34] J. S. Furnivall, Netherland India a Study of Plural Society. Cambridge University Press, Cambridge MA., 1939.

[35] M. Patchen, Diversity and Unity: Relations Between Racial and Ethnic Group. Nelson-Hall Publishers, 1999.

[36] K. K. Khoo, "Latar Belakang Sejarah Masharakat India dan China di Tanah Melayu," Jebat Malaysian J. Hist., vol. 1, pp. 14-23, 1972.

[37] N. M. Noor, "The Future of Malay-Chinese Relations in Malaysia," in Peace psychology in Asia, Springer US, 2009, pp. 161-172.

[38] Z. Othman, "Understanding Ethnic Conflict in Myanmar (Burma) from Human Right Perspective.pdf," Jebat Malaysian J. Hist. Polit. Strateg. Stud., vol. 31, no. 1, pp. 179-202, 2004.

[39] G. Hofstede, "Malaysian Culture Through the Lens of The 6-D Model@." [Online]. Available: https://geerthofstede.com/malaysia.html

[40] P. Fraternali and M. Tisi, "Identifying cultural markers for web application design targeted to a multi-cultural audience," Proc. - 8th Int. Conf. Web Eng. ICWE 2008, pp. 231-239, 2008.

[41] E. W. Gould, N. Zalcaria, and S. a. M. Yusof, "Applying culture to Web site design: a comparison of Malaysian andlnUS Web sites," 18th Annu. Conf. Comput. Doc. ipcc sigdoc 2000. Technol. Teamwork. Proceedings. IEEE Prof. Commun. Soc. Int. Prof. Commun. Conf. an, pp. 161-171, 2000.

[42] A. Asma, "Going Glocal-Cultural Dimensions in Malaysian Management.," 1996.

[43] C. I. Llanos and M. N. Muñoz, "Design Guidelines for Web Applications Based on Local Patterns," in ATIS '07 Proceedings of the 2007 Euro American conference on Telematics and information systems, 2007.

[44] P. M. Podsakoff, S. B. MacKenzie, J.-Y. Lee, and N. P. Podsakoff, "Common method biases in behavioral research: a critical review of the literature and recommended remedies.," J. Appl. Psychol., vol. 88, no. 5, pp. 879-903, 2003.

[45] A. Marcus, "User Interface Design and Culture," in Usability and Internationalization of Information Technology, CRC Press, 2005, pp. 51-78.

[46] M. O. Leavitt and B. Shneiderman, "Research-Based Web Design \& Usability Guidelines," 2006.

[47] A. Marcus and E. W. Gould, "Crosscurrents: Cultural Dimensions and Global Web User-Interface Design," Interact. ACM, vol. 7, no. 4, pp. 32-46, 2000.

[48] B. Shneiderman and C. Plaisant, Designing the User Interface: Strategies for Effective Human-Computer Interaction, vol. 5th, no. 2. Addison Wesley, 2010.

[49] T. W. MacFarland and J. M. Yates, "Kruskal--Wallis H-Test for Oneway Analysis of Variance (ANOVA) by Ranks," in Introduction to Nonparametric Statistics for the Biological Sciences Using R, Cham: Springer International Publishing, 2016, pp. 177-211.

[50] T. W. MacFarland and J. M. Yates, Mann--Whitney U Test. Cham: Springer International Publishing, 2016.

[51] R. A. Armstrong, "When to use the Bonferroni correction," Ophthalmic Physiol. Opt., vol. 34, no. 5, pp. 502-508, 2014. 